\title{
Algemeen verloskundige taken van de huisarts: een onderzoek naar de behoefte aan verloskundig onderwijs tijdens de huisartsopleiding
}

\author{
C.A. Trompert, M. Boek, K.H. Groenier, J.M. Koelewijn, F. Baarveld
}

\section{Samenvatting}

Inleiding: Steeds minder huisartsen zijn verloskundig actief. Hiermee wordt bedoeld dat zij steeds minder specifiek verloskundige taken verrichten (zoals bevallingen). Huisartsen zien ook de algemene verloskundige taken steeds minder als hún taak. In de praktijk worden zij echter wel geconfronteerd met klachten en aandoeningen bij zwangeren en kraamvrouwen. In het basiscurriculum tot huisarts krijgt verloskunde nauwelijks aandacht; slechts een beperkt deel van de artsen in opleiding tot specialist (aios) huisartsgeneeskunde volgt de keuzestage verloskunde. Dit onderzoek richtte zich op de volgende vraagstelling: 1) is er verschil in algemeen verloskundige kennis tussen verloskundig-actieve en niet verloskundig-actieve huisartsen en aios en 2) hebben huisartsen (in opleiding) behoefte aan een algemeen verloskundig onderdeel in het onderwijsprogramma van de huisartsopleiding?

Methode: Een kennistoets met aanvullende enquêtevragen werd verzonden aan 536 huisartsen en 33 aios huisartsgeneeskunde. Vijf groepen werden onderscheiden: verloskundig-actieve huisartsen, in het verleden verloskundig-actieve huisartsen, niet verloskundig-actieve huisartsen, aios met en aios zonder verloskundestage.

Resultaten: 241 respondenten vulden de enquête in. De gemiddelde toetsscore was 77,4\%. Verloskundig-actieve huisartsen en aios scoorden significant hoger dan de andere groepen. 93,8\% van de respondenten vond een algemeen verloskundig onderdeel in het onderwijsprogramma van de huisartsopleiding nodig.

Discussie en conclusie: Verloskundig-actieve huisartsen en aios hebben meer algemeen verloskundige kennis dan hun collega's. Daar de meerderheid van de respondenten vindt dat een algemeen verloskundig onderdeel in het onderwijsprogramma van de huisartsopleiding nodig is, bevelen wij de huisartsopleidingen in Nederland aan dit onderdeel op te nemen in het standaardonderwijsprogramma. (Trompert CA, Boek M, Groenier KH, Koelewijn JM, Baarveld F. Algemeen verloskundige taken van de huisarts: een onderzoek naar de behoefte aan verloskundig onderwijs tijdens de huisartsopleiding. Tijdschrift voor Medisch Onderwijs 2010;4(29):245-251.)

\section{Inleiding}

Steeds minder huisartsen zijn verloskundig-actief, dat wil zeggen dat steeds minder huisartsen specifieke verloskundige taken verrichten, te weten: het begeleiden van de bevalling en het verrichten van de reguliere controles tijdens de zwangerschap en het kraambed. Het percentage verloskundig-actieve huisartsen in Nederland is teruggelopen van 43\% in 1983 naar
5\% in 2004. ${ }^{1-3}$ Daarnaast rekenen steeds minder huisartsen algemeen verloskundige taken tot hún takenpakket. ${ }^{14}$ Dit zijn taken die iedere huisarts in principe zou moeten kunnen verrichten: advies en diagnostiek in het eerste trimester van de zwangerschap, waaronder de begeleiding van miskramen, en de herkenning en behandeling van pathologie tijdens de gehele zwangerschap en in het kraambed. ${ }^{4-7}$ Elke 
huisarts zal echter regelmatig te maken krijgen met morbiditeit bij zwangeren en kraamvrouwen die bij de eerstelijns verloskundige onder controle zijn en voor wie hulp van de huisarts wordt ingeroepen. Ook kunnen huisartsen tijdens avond-, nacht- en weekenddiensten geconfronteerd worden met acute pathologie waarvoor adequate kennis en spoedeisend handelen worden verlangd. ${ }^{8}$

In een normpraktijk wordt de huisarts jaarlijks gemiddeld 230 keer geconsulteerd voor klachten die betrekking hebben op anticonceptie en zwangerschap (hoofdstuk 'W' van de 'International Classification of Primary Care' - ICPC). ${ }^{9-10}$ Meer dan de helft hiervan betreft anticonceptie, maar daarnaast worden in een normpraktijk jaarlijks patiënten gezien in verband met bevestiging van zwangerschap $(n=21)$, subfertiliteit $(n=5)$, mastitis puerperalis $(n=2)$ en miskraam ( $n=2$ tot 3 ). Daarbij moet bedacht worden dat niet alle contactredenen van zwangeren in hoofdstuk 'W' zijn opgenomen. Een zwangere met een urineweginfectie zal bijvoorbeeld veelal zijn gecategoriseerd in hoofdstuk ' $U$ ', terwijl een urineweginfectie tijdens de zwangerschap wel degelijk consequenties voor die zwangerschap kan hebben en bij het voorschrijven van medicatie rekening gehouden dient te worden met de zwangerschap.

In een normpraktijk ziet de huisarts gemiddeld zes zwangerschapsgerelateerde spoedgevallen per jaar, zoals miskraam, extrauteriene graviditeit (EUG), dreigende vroeggeboorte, pre-eclampsie/HELLPsyndroom, abruptio placentae en placenta praevia. ${ }^{8}$ In 2000 betrof $3,7 \%$ van alle hulpvragen buiten kantooruren in de stad Groningen een klacht of aandoening uit hoofdstuk ' $W$ '. 11

In 1998 waren (vooral verloskundig-actieve) huisartsen van mening dat er in de huisartsopleiding te weinig aandacht werd besteed aan verloskundige kennis. Er werd gepleit voor een specifiek scholingsprogramma voor degenen die daadwerkelijk zwangerschap en bevalling willen begeleiden. ${ }^{15}$ Voor deze groep bestaat sinds 2002 een facultatieve stage verloskunde aan de huisartsopleidingen in Groningen en Leiden. ${ }^{2}$ Deze stage kan zowel door huisartsen in opleiding gevolgd worden als door afgestudeerde huisartsen. In de stage wordt aandacht besteed aan specifiek verloskundige taken, maar ook aan algemeen verloskundige kennis. Momenteel volgen 10-20 huisartsen (in opleiding) per jaar deze stage. Door veranderingen in de regelgeving rondom de stages tijdens de huisartsopleiding is het inpassen van de stage verloskunde moeilijker geworden.

Het doel van ons onderzoek is na te gaan of huisartsen en artsen in opleiding tot specialist (aios) huisartsgeneeskunde die nooit verloskundig-actief zijn geweest, voldoende algemeen verloskundige kennis hebben. Hiertoe vergeleken we hun kennis met die van huisartsen en aios die wel verloskundig-actief zijn (geweest) of de verloskundestage hebben gevolgd. Ook hebben we onderzocht of de huisartsen (in opleiding) meer algemeen verloskundige scholing nodig vinden. Met de uitkomst wilden we een uitspraak doen over de behoefte aan een algemeen verloskundig onderdeel in het standaardonderwijsprogramma van de huisartsopleiding. In dit onderzoek stond de volgende vraagstelling centraal:

- Is er verschil in algemeen verloskundige kennis tussen verloskundig-actieve en niet verloskundig-actieve huisartsen en aios huisartsgeneeskunde?

- Hebben huisartsen (in opleiding) behoefte aan een algemeen verloskundig onderdeel in het standaardonderwijsprogramma van de huisartsopleiding? 


\section{Methode}

\section{Type onderzoek}

Er werd een cross-sectioneel onderzoek verricht, bestaande uit een kennistoets en een korte enquête.

\section{Populatie}

In maart 2007 werd een kennistoets, met aanvullend een korte enquête, verzonden aan huisartsen en aios huisartsgeneeskunde. Er werd een aselecte steekproef $(n=300)$ getrokken uit het bestand van huisartsen in het adherentiegebied van het Universitair Medisch Centrum Groningen (Friesland, Groningen, Drenthe en Overijssel). Daarnaast werden alle bij de Vereniging voor Verloskundig Actieve Huisartsen (VVAH) geregistreerde huisartsen in Nederland ( $\mathrm{n}=250)$ aangeschreven. Er was een overlappende groep $(n=14)$. De groep aios bestond uit de derdejaars aios die tijdens de huisartsopleiding de verloskundestage hebben gevolgd in Groningen of Leiden in november 2006 $(n=17)$ en een groep derdejaars aios uit
Groningen die de verloskundestage niet hebben gevolgd $(n=16)$.

De deelnemers werden onderverdeeld in vijf groepen: verloskundig-actieve huisartsen, in het verleden verloskundig-actieve huisartsen, niet verloskundig-actieve huisartsen, aios huisartsgeneeskunde met verloskundestage en aios huisartsgeneeskunde zonder verloskundestage.

\section{Kennistoets}

De toets bestond uit negen casus met daarbij 22 juist/onjuist-vragen, evenredig verdeeld over de belangrijkste contactredenen in de ICPC, hoofdstuk 'W': zeven casus (19 vragen) betroffen zwangerschap en kraambed; één casus betrof een preconceptioneel consult en één casus (twee vragen) ging over abortus provocatus (zie Tabel 1). Voor het samenstellen van de toetsvragen is gebruik gemaakt van standaarden van het Nederlands Huisartsengenootschap (NHG) die betrekking hebben op zwangerschap, bevalling en kraambed en anticonceptie, en van toetsvragen die goedgekeurd zijn voor de Landelijke Huis-

Tabel 1. Score per casus naar ooit/nooit verloskundig actief.

\begin{tabular}{|c|c|c|c|c|}
\hline \multirow[t]{2}{*}{ Casus } & \multirow[t]{2}{*}{ Aantal vragen } & \multicolumn{2}{|r|}{ Score } & \multirow[t]{2}{*}{ p-waarde } \\
\hline & & $\begin{array}{c}V^{*} \\
\% \text { goed }\end{array}$ & $\begin{array}{c}\text { nooit VA* } \\
\% \text { goed }\end{array}$ & \\
\hline Mastitis puerperalis & 2 & 97,7 & 97,7 & NS \\
\hline Anticonceptie tijdens borstvoeding & 3 & 93,5 & 89,4 & NS \\
\hline HELLP-syndroom & 4 & 83,2 & 75,6 & 0,002 \\
\hline Interpretatie bloedonderzoek & 3 & 83,0 & 74,6 & 0,003 \\
\hline Prenatale diagnostiek & 2 & 80,1 & 68,8 & 0,011 \\
\hline Endometritis & 3 & 67,7 & 68,9 & NS \\
\hline Rhesusimmunisatie bij miskraam & 2 & 73,5 & 56,8 & $<0.001$ \\
\hline Preconceptioneel advies & 1 & 64,7 & 58,0 & NS \\
\hline Abortus provocatus & 2 & 58,5 & 58,0 & NS \\
\hline
\end{tabular}

* VA: nu en in het verleden verloskundig-actieve huisartsen en aios met verloskundestage Nooit VA: niet verloskundig-actieve huisartsen en aios zonder verloskundestage

$\$$ Mann Whitney $U$ test

NS: niet significant 
artsgeneeskundige Kennistoets. ${ }^{4}{ }^{12-14}$ De score wordt weergegeven als het percentage correct beantwoorde vragen.

\section{Enquête}

In de enquête werd gevraagd naar enkele achtergrondkenmerken van de respondenten en naar hun mening over de noodzaak van opname van een algemeen verloskundig onderdeel in het standaardonderwijsprogramma van de huisartsopleiding.

\section{Analyse}

De gegevens werden geanalyseerd met behulp van SPSS versie 12.0.1 (SPSS Inc., Chicago, IL, USA). Verschillen tussen categorische variabelen werden getoetst met Pearson's chi-kwadraat toets en verschillen tussen continue variabelen met de Student's t-toets, ANOVA of Mann-Whitney U test (bij niet normaal verdeelde variabelen). Er werd een significantieniveau van $\alpha=0.05$ (tweezijdig) gehanteerd. Normaliteit van de verdelingen werd met de Kolmogorov-Smirnovtoets en Q-Q plots beoordeeld. Correlatie bij niet normaal verdeelde variabelen werd berekend met behulp van Spearman's rangcorrelatie coëfficiënt.

\section{Resultaten}

\section{Populatie}

Van de 569 verstuurde vragenlijsten werden er 241 ingevuld geretourneerd (43\%). Van de 241 respondenten waren 81 verloskundig-actief huisarts, 55 in het verleden verloskundig-actief huisarts, 72 niet verloskundig-actief huisarts, 17 aios met verloskundestage en 16 aios zonder verloskundestage. De periode dat huisartsen gestopt waren met verloskunde varieerde van 0 tot 29 jaar; voor de helft van hen was dit zes jaar of korter.

\section{Kennistoets}

De gemiddelde score van de totale groep deelnemers was 77,4\% (zie Figuur 1). De score van de verloskundig-actieve huisartsen $(80,6 \%$; $95 \%$-BI 78,5-82,6\%) en die van de aios met verloskundestage $(81,0 \%$; $95 \%$ BI 77,6-84,5\%) was significant hoger dan de score van de niet verloskundig-actieve huisartsen (73,7\%; 95\%-BI 71,7-75,8\%).Tussen de score van in het verleden verloskundigactieve huisartsen en het aantal jaren dat ze niet meer verloskundig-actief zijn, werd geen significant lineair verband aangetoond $(\mathrm{r}=0.23$; Spearman's ro).

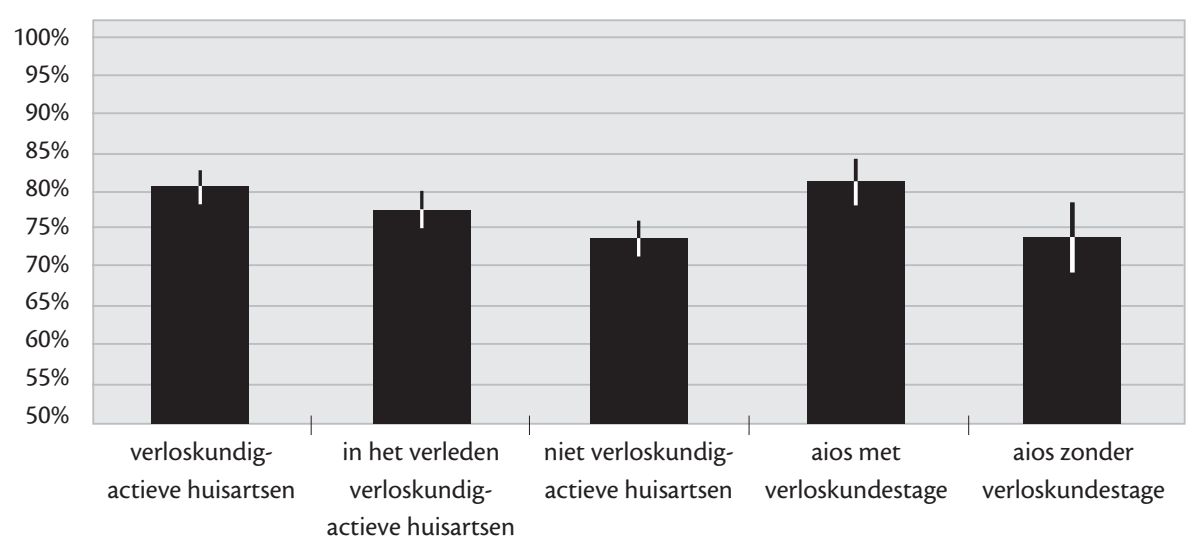

Figuur 1. Scores kennistoets met 95\%-betrouwbaarheidsintervallen. 
Tabel 1 geeft een overzicht van de negen casus uit de toets, waarin de scores worden vergeleken tussen wel/ooit verloskundig-actieve huisartsen en nooit verloskundig-actieve huisartsen en aios. De scores voor verloskundig-actieve huisartsen en aios waren hoger bij de casus over het HELLP-syndroom, rhesusimmunisatie bij miskraam, interpretatie bloedonderzoek en prenatale diagnostiek. De scores per casus varieerden van 58\% (abortus provocatus) tot $97,7 \%$ (mastitis puerperalis).

\section{Enquête}

Van de totale groep van 241 deelnemers vonden 226 (93,8\%) dat er wél en 14 deelnemers dat er geen algemeen verloskundig onderdeel in het standaardonderwijsprogramma van de huisartsopleiding zou moeten komen; één deelnemer had geen mening. Van de verloskundig-actieve huisartsen was $97,5 \%$ voor verloskundig onderwijs, van de in het verleden verloskundig-actieve huisartsen $96,3 \%$, van de beide groepen aios $100 \%$ en van de niet verloskundig-actieve huisartsen $86,1 \%$ ( $\mathrm{p}<0.001$ ten opzichte van alle andere groepen).

\section{Discussie}

Onze studie laat zien dat verloskundig-actieve huisartsen en aios die de stage verloskunde hebben gevolgd significant meer algemeen verloskundige kennis hebben dan huisartsen die nooit verloskundig-actief zijn geweest. Een ruime meerderheid (94\%) vindt dat algemeen verloskundige kennis een standaardonderdeel moet zijn van de basisopleiding tot huisarts. Dit geldt ook voor de meeste huisartsen die nooit verloskundig-actief zijn geweest $(86 \%)$. Welke toetsscore voldoende is om de algemeen verloskundige kennis als voldoende te kunnen beschouwen, is op basis van onze studie niet vast te stellen. Om een zo hoog mogelijke respons te krijgen is gekozen voor een toets van beperkte omvang waardoor de casus slechts een selectie vormen uit een grote hoeveelheid verloskundige vraagstukken waarmee huisartsen worden geconfronteerd. Het verschil van 7\% (bij een SD van 9.3\%) is niet bijzonder groot en de relevantie hiervan is twijfelachtig.

De verschillen tussen wel (ooit) en niet verloskundig-actieve huisartsen en aios zijn significant bij de casus die de zwangerschap betreffen (HELLP-syndroom, interpretatie bloedonderzoek, rhesusimmunisatie bij miskraam en prenatale diagnostiek). De casus over mastitis en anticonceptie werden het best gemaakt en er was geen verschil tussen verloskundig-actieven en niet actieven; deze onderwerpen komen ook buiten de zwangerschap voor. De casus over preconceptioneel advies en ongewenste zwangerschap werden het minst goed gemaakt, maar ook hier was geen verschil te zien tussen de groepen. Als dit laatste betekent dat veel huisartsen een lacune hebben in deze gevoelige problematiek, is dat een belangrijk aandachtspunt.

Het aantal jaren dat een huisarts niet meer verloskundig-actief is, blijkt in deze studie niet te correleren met de behaalde score. Hieruit kan geconcludeerd worden dat het aantal niet verloskundig-actieve jaren na het stoppen met de begeleiding van zwangerschap en bevalling, niet leidt tot een geleidelijke afname van de algemeen verloskundige kennis. Eenmaal vergaarde kennis blijft blijkbaar reproduceerbaar.

Er is gekozen voor het versturen van een vragenlijst naar huisartsen in NoordNederland. Daarom is niet duidelijk in hoeverre de algemeen verloskundige kennis van de niet verloskundig-actieve huisartsen representatief is voor huisartsen in de rest van Nederland. Ook kan in onze studie enige selectiebias zijn opgetreden in de groep niet verloskundig-actieve 
huisartsen doordat wellicht met name huisartsen met interesse in de verloskunde de vragenlijst geretourneerd hebben. Dit zou kunnen leiden tot enige overschatting van het percentage huisartsen dat meer aandacht voor algemeen verloskundige kennis tijdens de basisopleiding tot huisarts nodig vindt; het blijft echter hoe dan ook een ruime meerderheid. Om te onderzoeken of de verschillen in kennis ook daadwerkelijk relevant zijn voor de praktijk, is een andere vorm van onderzoek nodig, bijvoorbeeld een audit van casuïstiek die zich in de praktijk heeft voorgedaan.

\section{Conclusie}

Steeds minder huisartsen voeren specifiek of algemeen verloskundige taken uit. Huisartsen zullen echter altijd geconfronteerd worden met een aanzienlijk aanbod van verloskundige klachten en aandoeningen. Daaronder bevinden zich potentieel gevaarlijke ziektebeelden waarbij adequate kennis en spoedeisend handelen worden verlangd. Onze studie geeft een indicatie dat niet verloskundig-actieve huisartsen minder kennis van verloskunde hebben dan verloskundig-actieve huisartsen en aios die geschoold zijn in verloskunde. Ook komt naar voren dat huisartsen in Nederland meer aandacht voor algemeen verloskundige kennis in het basiscurriculum van de huisartsopleiding wel wenselijk vinden. Een inventarisatie bij de acht opleidingen (juni 2009) wees uit dat verloskundig onderwijs in geen van de opleidingen een vast programmaonderdeel is.

Wij bevelen de huisartsopleidingen in Nederland aan om naast de facultatieve verloskundestage een algemeen verloskundig onderdeel op te nemen in het standaardonderwijsprogramma voor aios huisartsgeneeskunde. Ook voor niet verloskundigactieve huisartsen is het raadzaam zich door middel van nascholing te blijven verdiepen in verloskundige onderwerpen.

\section{Literatuur}

1. Wiegers TA, Hingstman L. Verloskundig actieve huisartsen. Huisarts Wet 2000;43(10):430-3. [General practitioners that regularly provide obstetric care. The General Practitioner and Science 2000;43(10):430-3].

2. Wiegers TA. Steeds minder huisartsen verloskundig actief. Huisarts Wet 2003;46(8):432-4. [A continuing decrease in obstetric care provision by general practitioners. The General Practitioner and Science 2003;46(8):432-4].

3. Wiegers TA. General practitioners and their rol in maternity care. Health Policy 2003; 66(1):51-59.

4. Coffie DSV, Wiegers TA, Schellevis EG. Verloskunde uit eerste lijn - Verschuiving in taakopvatting van huisartsen. Med Contact 2003;58(20): 803-4. [Obstetrics in primary care - A shift in GP's views of their tasks. Medical Contact 2003;58 (20):803-4].

5. Oldenziel JH, Flikweert S, Daemers DOA, Groenendijk B, Lo Fo Wong SH, Wiersma Tj. NHGStandaard Zwangerschap en kraamperiode, M32 (eerste herziening). Huisarts Wet 2003;46(7):36987. [Guideline of the Dutch Society of General Practitioners on Pregnancy and postnatal period, M32 (first revised edition). The General Practitioner and Science 2003;46(7):369-87].

6. Weyts MCG, Van der Horst FGEM. Algemeen verloskundige taken van de huisarts tijdens het eerste trimester van de zwangerschap. Uitvoering, verslaglegging en gegevensoverdracht. Huisarts Wet 1994;37(13):566-68. [General obstetric tasks of the GP during the first trimester of pregnancy. Performance, reporting and information transfer. The General Practitioner and Science 1994;37 (13):566-68].

7. Flikweert S, Lagro-Janssen T. Kind en badwater: metafoor voor huisarts en verloskunde? Huisarts Wet 2000;43(2):55-8. [Child and bathwater? An apt metaphor for the GP and obstetrics? The General Practitioner and Science 2000;43(2):55-8].

8. Dekker CJ, Springer MP. Spoedgevallen bij zwangere vrouwen in de huisartspraktijk. Huisarts Wet 1997;40(6)248-53. [Emergencies in primary care involving pregnant women. The General Practitioner and Science 1997;40(6):248-53].

9. Lamberts H, Wood M (eds). ICPC. International Classification of Primary Care. Oxford: Oxford University Press; 1993.

10. Schellevis FG, Westert GP, de Bakker DH, Groenewegen PP, Van der Zee J, Bensing JM. Tweede Nationale Studie naar ziekten en verrichtingen in de huisartspraktijk. Utrecht/Bilthoven: NIVEL / RIVM; 2004. [Second National Study of diseases and care provision in primary care. Utrecht/Bilthoven: NIVEL/RIVM, 2004].

11. Post J. Aangeboden morbiditeit bij grootschalige huisartsenzorg buiten kantooruren in de stad. 
Rijksuniversiteit Groningen, 2004. [Proefschrift]. [Morbidity presented in out of hours large scale primary care in an urban area. University of Groningen, 2004; dissertation].

12. Beijderwellen L, Van der Does FEE, Kardolus GJ, Lobo C, Van Sluisveld ILL, Boukes FS. NHGStandaard Hormonale anticonceptie, M02 (tweede herziening). Huisarts Wet 2003;46(10): 552-63. [Guideline of the Dutch Society of General Practitioners on hormonal contraception, M02 (second revised edition). The General Practitioner and Science 2003;46(10): 552-63].

13. Flikweert $S$, Wieringa-de Waard M, Meijer LJ, De Jonge A, Van Balen JAM. NHG-Standaard Miskraam, M03 (tweede herziening). Huisarts Wet 2004;47(3):147-55. [Guideline of the Dutch Society of General Practitioners on miscarriages, M03 (second revised edition). The General Practitioner and Science 2004;47(3):147-55].

14. Dukkers van Emden DM, Smeenk RCJ, Verblackt HWJ, Westerveld MC, Wiersma Tj. NHG-Standaard Het Spiraaltje, M14 (eerste herziening). Huisarts Wet 2000;43(7):314-20. [Guideline of the Dutch Society of General Practitioners on the IUD, M14 (first revised edition). The General Practitioner and Science 2000;43(7):314-20].
De auteurs:

Drs. Chris A Trompert is huisarts. *

Drs. Mariska Boek is huisarts. *

Dr. Klaas H. Groenier is statisticus/epidemioloog.

Dr. Joke M. Koelewijn is verloskundige en coördinator stage verloskunde.

Dr. Frank Baarveld is huisarts en hoofd huisartsopleiding.

Allen zijn verbonden aan de Huisartsopleiding van het Universitair Medisch Centrum Groningen.

* Ten tijde van dit onderzoek huisarts in opleiding.

\section{Correspondentieadres:}

J.M. Koelewijn, Afdeling Huisartsgeneeskunde, huisartsopleiding UMCG, postbus 196, 9700 AD Groningen. Tel. 050-3638576/71;

e-mail:j.m.koelewijn@med.umcg.nl

Belangenconflict: geen gemeld

Financiële ondersteuning: geen gemeld

\section{Summary}

Introduction: The involvement of general practitioners (GPS) in obstetric care is diminishing, with a decrease in the number of deliveries performed and general obstetrics care provided by GPs, including prenatal and postnatal care for women with different diseases and complaints. Little attention is paid to obstetrics during postgraduate training in primary care. The elective course in obstetrics is only attended by a minority of GP trainees. Research questions: does general knowledge of obstetrics differ between GPS and GP trainees that habitually perform obstetric tasks and GPS that do not perform such tasks?

Do GPS and GP trainees perceive a need for training in general obstetrics during postgraduate training in primary care?

Method: A knowledge test and an additional questionnaire were sent to 536 GPs and 33 GP trainees. Five groups were distinguished: GPs that habitually perform specific obstetric tasks, GPs that habitually performed such tasks in the past, GPs who had never performed obstetric tasks and GP students that had and had not attended the elective course in obstetrics during postgraduate training.

Results: 241 GPS and GP trainees responded. The mean test score was 77.4\%. The respondents that habitually performed obstetric tasks had significantly higher scores compared to the other groups. $93.8 \%$ of the respondents indicated that general obstetric training should be included in postgraduate training in primary care.

Discussion and conclusion: GPs and GP trainees that habitually perform obstetric tasks know more about general obstetrics compared to their colleagues who do not perform such tasks. A majority of the respondents thought that training in general obstetrics should be part of postgraduate training. Based on these findings, we recommend that the Departments of Primary Care in the Netherlands should incorporate general obstetric training as a mandatory component in their postgraduate training programmes. (Trompert CA, Boek M, Groenier KH, Koelewijn JM, Baarveld F. The GP's role in general obstetric care: should general obstetrics be part of postgraduate training programmes in primary care. Netherlands Journal of Medical Education 2010;4(29):245-251.) 